\title{
The Impact of Materials and Maintenance Considerations during the Design Stage of Public Buildings in Oman
}

\author{
S. Al Rubaiey ${ }^{1}$, N. Md Ulang ${ }^{2, a}$, F. Baharum ${ }^{3}$ \\ ${ }^{1,2,3}$ School of Housing, Building and Planning, Universiti Sains Malaysia, 11800, Penang, Malaysia
}

\begin{abstract}
The purpose of this study is to describe the experiences of architects and civil engineers in the Sultanate of Oman regarding building maintenance during the design of public buildings. This exploratory and descriptive study used a qualitative approach, drawing data from focus groups in particular, to develop a rich and in-depth description of the designers' building maintenance experiences. Structured interviews were conducted with 15 participants from architecture and civil engineering fields, from which, the interviewees shared the viewpoint that maintenance functions entirely separate from the design and construction process itself, but that it is, in fact, an integral part of the design process and post-occupancy stage. The designer should plan for sufficient maintenance for the whole building life cycle. However, some elements are more difficult to maintain in Oman than in other regions such as roofs, facades and the substructure of buildings. The results showed that salt is the most challenging environmental factor that could cause building defects. This was followed by solar heat, moisture from below ground and, lastly, rain. Most of these defects occurred during the buildings' post-occupancy phase and were related to inappropriate or poor design. The results also suggested that deficiencies caused by thermal expansion came in the form of cracks, followed by paint decay, dampness, and staining.
\end{abstract}

\section{Introduction}

Building maintenance is a major focus in most countries to assure proper building performance. The performance of any type of building is attained by meeting certain standards and quality of design [1]. Meeting the standards and planning a quality design are more effective when done during the design process as well as in the post-occupancy stage [2]. In the Sultanate of Oman, designers, property managers, owners and the department of public works are responsible for overseeing the maintenance work of a building. Despite this, it is really the architects and civil engineers who are the main players in maintenance work as they maintain the building's performance and address users' needs. More specifically, their input is most crucial during the design process, when design solutions are still maturing and have room for alterations. For instance, material specifications, detailed drawings, and costs can be prepared and easy managed before the final design solution is settled. Sufficient planning for maintenance in the early stages of design could protect the building from severe defects and make the maintenance process an easy task in future stages of design and

\footnotetext{
${ }^{\mathrm{a}}$ Corresponding author : norhidayah.mu@usm.my
} 
throughout the building's life cycle. Design influences the performance and physical characteristics of the building as well as its durability to withstand environmental elements and social interferences [3]. However, maintenance issues become more critical for public buildings when the facility is operated at its optimum capacity to serve the public intensively. Although extensive research has been carried out on building maintenance in general, there remains a lack of research focusing on the maintenance of public buildings in the Sultanate of Oman. Most public buildings and infrastructures have been neglected by subsequent tenures of government comparing with the private sectors [4]. Therefore, the purpose of this study was to describe the experiences of architects and civil engineers in the Sultanate of Oman regarding building maintenance during the design stage of public buildings. The research questions guiding the study were as follows: 1) Do you think that maintenance functions are often separate from the construction process? 2) Which of a building' elements are the most difficult to maintain? 3) Which environmental issues pose a challenge when designing for easy maintenance? 4) What building deficiencies related to inappropriate or poor design occur the most during postoccupancy?

\section{Methodology}

Since the purpose of this study was to describe the experiences of architects and civil engineers in the Sultanate of Oman regarding building maintenance during the design of public buildings, this exploratory and descriptive study followed a qualitative approach. In particular, focus groups were used to develop a rich and in-depth description of the designers' building maintenance experiences. The site for the study was at government organizations that specialized in public building construction and management. These organizations operate different types of public construction projects in the Sultanate of Oman and employ groups of designers. A segmented sample of designers was used for this study. Morgan [4] defined segmentation as a way to manage group composition to match carefully chosen categories of participants. The fifteen participants that participated in this study were drawn from a pool of architects and civil engineers. Structured interviews (researcher-administered surveys) were used as a qualitative research method [5]. The aim of this approach was to ensure that each interviewee be presented with exactly the same questions and in the same order [6]. The selected participants were contacted by email and phone with invitations to participate individually and to sign an informed consent document. The sessions were audiotaped to ensure complete collection of the data. The researcher then took written field notes to record his impressions of participants' responses.

\section{Results and Discussions}

Structured interviews with 15 participants revealed that 53\% of them were architects and $47 \%$ were civil engineers. Experience plays an important role in applying the factors affecting maintenance during the different stages of design. Each project has its own set of circumstances that differ from other projects. As such, special treatment based mainly on experience is required. Most of the participants $(86.7 \%)$ had experience of more than 10 years while $13.3 \%$ of the participants had experience of 6 to 10 years (Table 1).

Despite the participants' experience, they expressed different opinions regarding the connection between maintenance functions and the construction process. They were asked: "Do you think that maintenance functions are often separate from the construction process?" $33 \%$ of them agreed that it is a separate process, but $20 \%$ of them found maintenance functions to be sometimes separate from the construction process. These results are consistent with those of the Royal Institute of British Architects' [14] plan of work, which considers maintenance to be a separate function from the construction process and practical completion stage.

On the other hand, the results showed that $7 \%$ of the participants found maintenance functions to be almost never separate from the construction process, and $40 \%$ found maintenance functions to be never separate from the construction process (Figure 1). The later portion of participants opposed the idea that maintenance functions are an essential part of the design stages. Miles [2] explained that, 
though some may agree that maintenance functions are entirely separate from the design and construction process itself, they are in fact an integral part of the design process and post-occupancy stage. This is the reason why designers need to consider maintenance functions in the early stages of design as well as in the post-occupation stage.

Table Error! No text of specified style in document.1. Participant Characteristics

\begin{tabular}{|c|c|c|c|c|}
\hline Interviewees & Profession & Experience & Field of work & Training \\
\hline P1 & Architect & More than 10 years & Architecture & Sometimes \\
\hline $\mathrm{P} 2$ & Civil Engineer & More than 10 years & Structural engineer & Never \\
\hline P3 & Civil Engineer & $6-10$ years & Structural engineer & Often \\
\hline P4 & Architect & More than 10 years & Architecture & Never \\
\hline P5 & Architect & More than 10 years & Architecture & Never \\
\hline P6 & Architect & More than 10 years & Architecture & Never \\
\hline P7 & Architect & More than 10 years & Engineering interior design & Often \\
\hline P8 & Architect & More than 10 years & Architecture & Rarely \\
\hline P9 & Architect & $6-10$ years & Architecture & Never \\
\hline $\mathrm{P} 10$ & Civil Engineer & More than 10 years & $\begin{array}{c}\text { Soil and water } \\
\text { management }\end{array}$ & Sometimes \\
\hline P11 & Civil Engineer & More than 10 years & Building technology & Sometimes \\
\hline $\mathrm{P} 12$ & Civil Engineer & More than 10 years & Building technology & Sometimes \\
\hline P13 & Civil Engineer & More than 10 years & Structural engineer & Sometimes \\
\hline P14 & Architect & More than 10 years & Architecture & Never \\
\hline P15 & Civil Engineer & More than 10 years & Building technology & Rarely \\
\hline
\end{tabular}

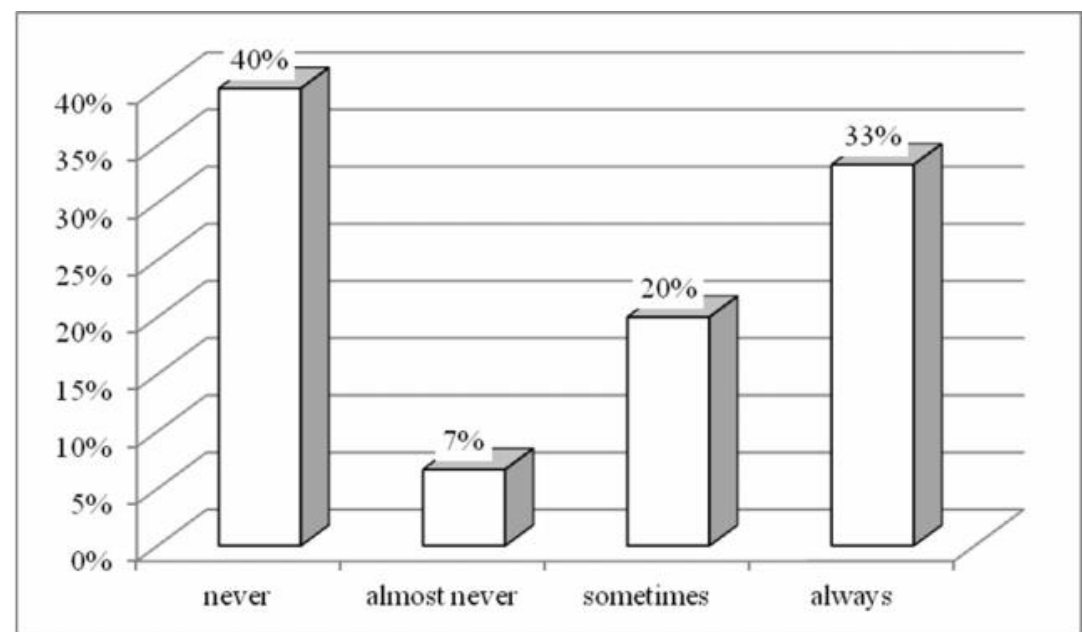

Figure 1: Maintenance functions to be separated from the construction process

The responsibilities assigned to the architect during the design of a project are substantial. The architect should know every single detail and extend his or her knowledge to predict which parts of the facility will require special maintenance in further stages of the design. Based on that, the architect will be able to draw accurate plans for sufficient maintenance. However, there are some elements that are more difficult to maintain than others. The participants were asked: "Which elements of a building 
are the most difficult to maintain?" The answers showed that the most difficult part of maintenance was the roof of the building with an agreement of $47 \%$. Roofs of buildings in Oman are typically flat and exposed to varying temperatures as the climate in Oman differs from region to region. In the coastal areas, the weather in summer is hot with an air temperature of about $40^{\circ} \mathrm{C}$ and humidity as high as $70 \%$. Meanwhile, it is hot and dry with an air temperature of about $45^{\circ} \mathrm{C}$ in the inner areas of Oman. The summer season begins in April and lasts until the end of October. These discrepancies in temperature during summer constantly cause cracks in concrete roofs which are difficult to maintain. Even advanced maintenance procedures could be spoiled by heat from the sun. The flat roofs that dominate almost all buildings in Oman are exposed directly to the sun light throughout the whole day and require regular inspections and maintenance. Building facades and sub-structures were both selected as the second most difficult maintenance issue with a vote of $20 \%$ each. In such a hot and dry climate, the impact of continuous sunshine on building facades accentuates the problem of thermal exposure. The sub-structure of a building is also threatened by high levels of humidity absorbed from the soil. The difficulty in maintaining facades and sub-structures of buildings is caused by limited access to these elements in the first place. Finally, $13 \%$ of those questioned selected floors as the most difficult maintenance issue and 7\% voted for each of the following elements: walls, service installations, structural element of the building, and MEP works (see Figure 2). For the purpose of proper future maintenance, designers should take into consideration the effectiveness of building treatments as a means of combating the severity of environmental conditions in addition to preparing for easy accessibility to different elements of a building during the design stage.

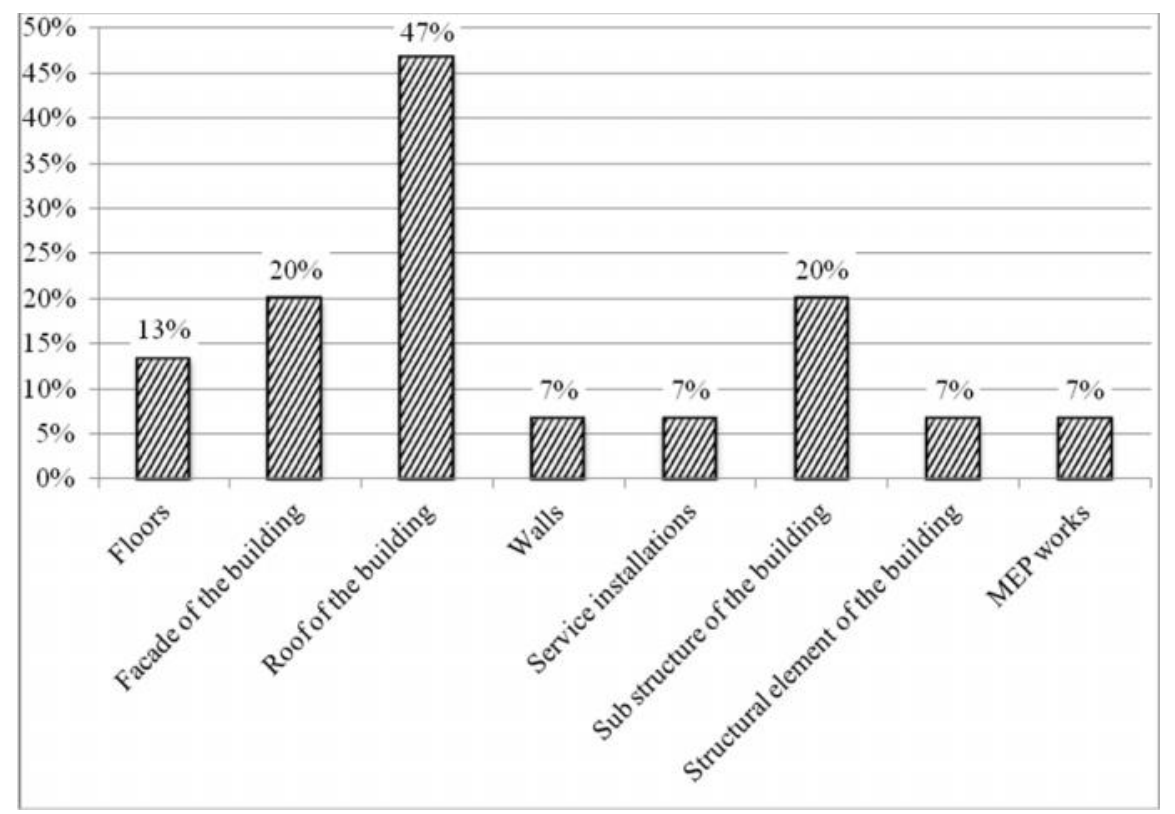

Figure 2. Building elements that are difficult to maintain

There are different environmental issues that threaten the durability of building materials. The participants were asked: "Which of the following environmental issues are challenging when designing for easy maintenance?" $73 \%$ of the answers showed that salt was the main challenging factor causing building defects. Solar heat was chosen as the second environmental factor that causes building defects with a vote of $53 \%$. Moisture from the ground came in as the third challenging factor with an agreement of $40 \%$. Lastly, $27 \%$ agreed that rain is a challenging factor causing building defects that require continues maintenance work (Figure 3). Essentially, all of these factors work together and cause different kinds of building defects. For instance, the base of a building absorbs part of its dampness from water that exists in the surrounding ground. This dampness carries an amount of salt into the walls of the building. Solar heat and wind circulation vaporize the dampness in hot 
weather and leave the salt stored in the building's structure. The repetition of this process causes wall cracks, dissolution of painting, as well as growth of fungi and bacteria over time. Moreover, when metal is not coated well or has scratches, salty dampness could spread and cause corrosion and defects.

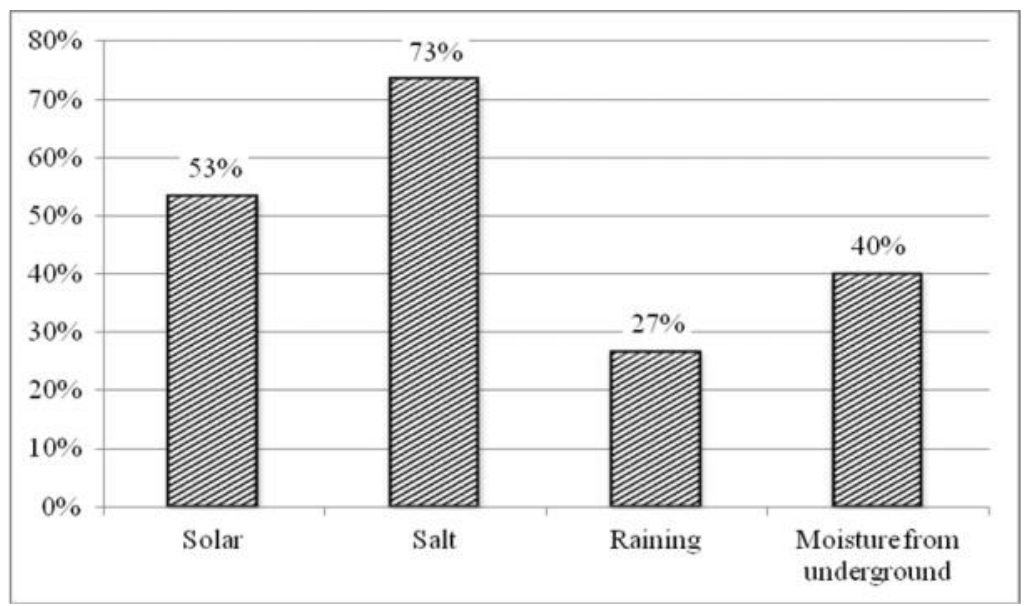

Figure 3. Environmental issues that are challenging when designing for easy maintenance

Most building deficiencies became more obvious during post-occupancy. This was mainly due to inappropriate or poor design. When the participants were asked Q4.4.3: "What building deficiencies related to inappropriate or poor design occurred most during post-occupancy?" $60 \%$ selected thermal expansion. 33\% agreed that paint decay occurred during post-occupancy. $27 \%$ chose dampness and $13 \%$ selected cracks. Lastly, 7\% chose staining (Figure 4). The results indicate that thermal expansion is the most important factor in design. Thermal expansion is the tendency of matter to change in volume in response to a change in temperature [7]. Thermal expansion causes cracks which follow the mortar joints running between the windows in facades. The brickwork expands in hot weather; when the weather changes and the brickwork cool, it shrinks. The shrinking brickwork cannot pull the building back into shape, so it cracks at the weakest point. These cracks could also occur on flat, concrete roofs, thereby causing severe building defects. Treatment for thermal expansion can be done by making gaps with expansion joints in certain parts of the building, then filling the gaps with rubber. This is to allow the building to expand and contract [8].

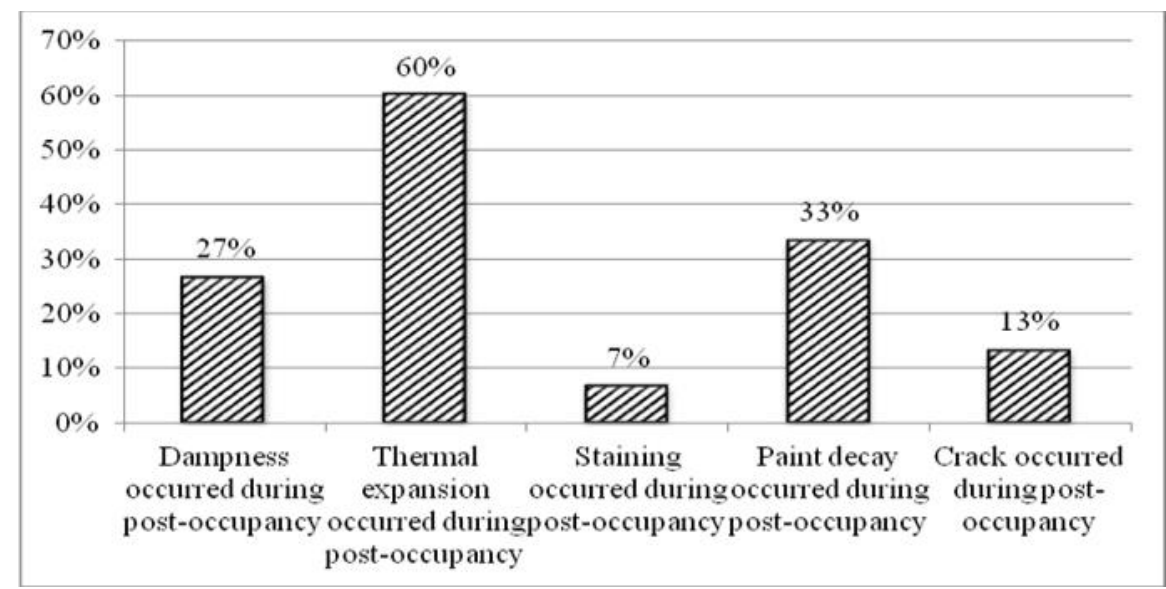

Figure 4. Most building deficiencies occurred during post-occupancy and were related to inappropriate or poor design 
Paint decay is caused by high levels of dampness and a lack of air circulation. High levels of dampness create unhealthy spaces and offer an ideal environment for fungi and bacteria to grow. Cracks that occurred during post-occupancy were caused as a result of poor quality control mechanisms put in place by the designer. Wall cracks were indicated by participants as one of the structural defects found in some building units. Aigbavboa [9] stated that walls act as a support system for the roof and should be constructed from good quality materials, otherwise the walls will not be strong and will crack. Staining occurred during post-occupancy as a result of low quality finishes and insufficient cleaning procedures. This defect is more obvious in public buildings rather than private houses. Staining and water damage were observed on the walls and floors of public toilets, as washrooms are more vulnerable to staining. Generally, a lack of interior and exterior finishes in housing units influenced the satisfaction levels of the respondents.

\section{Conclusion}

This research was conducted among 15 veterans in the field of construction who work in governmental organizations in the Sultanate of Oman. These experts shared the common view point that maintenance functions partially separate from the design and construction process itself, but that it is, in fact, an integral part of the design process and post-occupancy stage. Planned materials selection during the design phase could help prepare for maintenance functions in future stages of post-occupation. The responsibility of selecting materials is often scattered between many parties in construction projects. While this responsibility is mostly placed on the architect, being the originator of the design, other parties such as civil engineers, mechanical engineers, electrical engineers and decorators are also partially involved in material selection and maintenance functions. The architect should know every single detail of the project and extend his or her knowledge to predict which parts of the facility will require special maintenance in further stages of the design. Based on that, the architect will be able to draw accurate plans for sufficient maintenance, as most of a building's deficiencies do not become very obvious until the post-occupancy stage. The main environmental factors in Oman that cause building defects are salt, followed by sun heat, then moister from the ground. Rain could also cause building defects, but is less likely than any one of the previous factors. Finally, thermal expansion, paint decay, dampness, and cracks appearing on walls and ceilings are signs of inappropriate or poor design.

\section{References}

1. Shah-Ali, A., et al., The Effect of Design on Maintenance for School Buildings in Penang, Malaysia. Structural Survey, 2013. 31(3): p. 194-201.

2. Miles, D., A manual on Building Maintenance. Vol. 11976. 1976: Intermediate Technology Publications LTD.

3. Ramly, A., N.A. Ahmad, and N.H. Ishak, The effects of design on the maintenance of public housing buildings in Malaysia-part two. Building engineer, London association of building engineers, 2006: p. 34-36.

4. Morgan, D.L., Focus groups. Annual review of sociology, 1996: p. 129-152.

5. Kvale, S. and S. Brinkmann, Interviews: Learning the craft of qualitative research interviewing. 2nd ed. 2009: SAGE Publications, Inc.

6. Silverman, D., Interpreting qualitative data. 2011: SAGE Publications, Inc.

7. RIBA. Royal Institute of British Architects. 2013 [cited 2013; Available from: http://www.architecture.com/Home.aspx.

8. Tipler, P.A. and G. Mosca, Physics for scientists and engineers. 9th ed. 2007: Cengage Learning.

9. Aigbavboa, C.O., An evaluation of the post occupancy experience of housing subsidy beneficiaries in South Africa: a case study of Gauteng, in Faculty of engineering and the built environment. 2010, University of Johannesburg: Republic of South Africa. 